\title{
DETERMINING GEOPHYSICAL PROPERTIES OF A NEAR-SURFACE CAVE THROUGH INTEGRATED MICROGRAVITY VERTICAL GRADIENT AND ELECTRICAL RESISTIVITY TOMOGRAPHY MEASUREMENTS
}

\author{
Marco Gambetta ${ }^{*}$, Egidio Armadillo², Cosmo Carmisciano ${ }^{1}$, Paolo Stefanelli ${ }^{1}$, Luca Cocchi \\ AND FABIO CARATORI TONTINI ${ }^{3}$
}

\begin{abstract}
Vertical-gradient microgravity and electrical-resistivity tomography geophysical surveys were performed over a shallow cave in the Italian Armetta Mountain karst area, close to the Liguria-Piedmont watershed. The aim of this study was to test the geophysical response of a known shallow cave. The shallowest portion of the cave exhibits narrow passages and, at about 30 meters below the entrance, a fossil meander linking two large chambers, the target of the geophysical survey. The integrated results of the two surveys show a clear geophysical response to the cave. The surveys exhibited high resistivity values and a negative gravity anomaly over the large cave passages. This work confirms the ability of these geophysical techniques to give the precise location of the voids, even in complex environments. The application of these techniques can be successful for site surveying where the presence of hollows may be expected.
\end{abstract}

\section{INTRODUCTION}

Geophysical techniques provide quick, low-cost imaging of voids, and can play a key role in understanding epikarst. This understanding is crucial because karst conduits may conduct pollutants toward groundwater reservoirs and contaminate vulnerable water resources (Field, 1993). Moreover, collapse of underground voids may result in extensive damage to property and danger to people (Waltham, 2005). In this paper we show the results of a geophysical survey conducted over a shallow cave developed under the Cartei da Colla plain in the Mount Armetta karst, which is located near the Ligurian-Piedmont watershed in northwestern Italy. The aim of this study is to contribute to the body of void-detection techniques. This geophysical survey consisted of a multi-electrode electrical-resistivity tomographic survey combined with a vertical-gradient gravity survey. The geophysical imaging of underground voids was verified by comparison with the authors' measurements of the cave dimensions. Among various geophysical methods, electrical-resistivity tomography (ERT) and microgravity vertical-gradient (MVG) were chosen because of their recognized ability to detect shallow features such as hollows and cave voids. In particular, the MVG technique emphasizes shallow gravity anomalies with a strong reduction in geologic noise to allow determination of the horizontal position of voids. The high resolution ERT, conversely, outlines the shape and vertical distribution of the hollows, which appear as high-resistivity volumes.

\section{Area Geology}

The geophysical survey was carried out in Cartei da Colla plain (Figs. 1 and 2), located at $1400 \mathrm{~m}$ above sea level and encompassing more than $9 \mathrm{~km}^{2}$ in the Mount Armetta karst complex in Val Pennavair, Italy, close to the Liguria-Piedmont watershed. The karst aquifer feeds a spring used by local municipalities for drinking water supplies.

The karst terrane belongs to the Caprauna Armetta tectonic unit, which is a cover nappe emplaced during the Briançonnais orogeny on the external margin of the Ligurian Briançonnais terrane. The unit features four superimposed deformations that produced large recumbent isoclinal folds (phase 1 folds in Fig. 2) associated with a strong axial-plane cleavage and a southwest-trending lineation. These folds can be related to a southwestdirected overthrust shear. The second phase of deformation (phase 2 folds in Fig. 2) yielded open to moderately tight folds with subvertical axial planes that are overturned towards the northeast. The later deformations are longwavelength open folds affecting only the large-scale setting of the nappe (Menardi-Noguera, 1988). Folds from the two phases constrained the cave's evolution. The large room located at the intersection of the phase 1 and 2 anticlines (Fig. 2) has been interpreted as the topmost part of a pit, now filled with collapse debris. This large pit appears to have evolved over a dome-like structure featuring a pervasive axial-plane cleavage. The cave, dropping from the entrance at $1395 \mathrm{~m}$ above sea level to approximately $1200 \mathrm{~m}$, also seems to be guided both by the rocks' brittle deformations and the stratigraphy. The deepening conduits follow both the strata dip direction of $20^{\circ}$ and a set of

\footnotetext{
* Corresponding author, marco.gambetta@ingv.it

${ }^{1}$ INGV - Via Pezzino Basso 2 Fezzano di Portovenere (SP) — Italy

${ }^{2}$ University of Genova, DIP.TE.RIS, V.le Benedetto XV, Genova - Italy

${ }^{3}$ GNS Science, 1 Fairway Dr, Avalon, Lower Hutt, New Zealand
} 


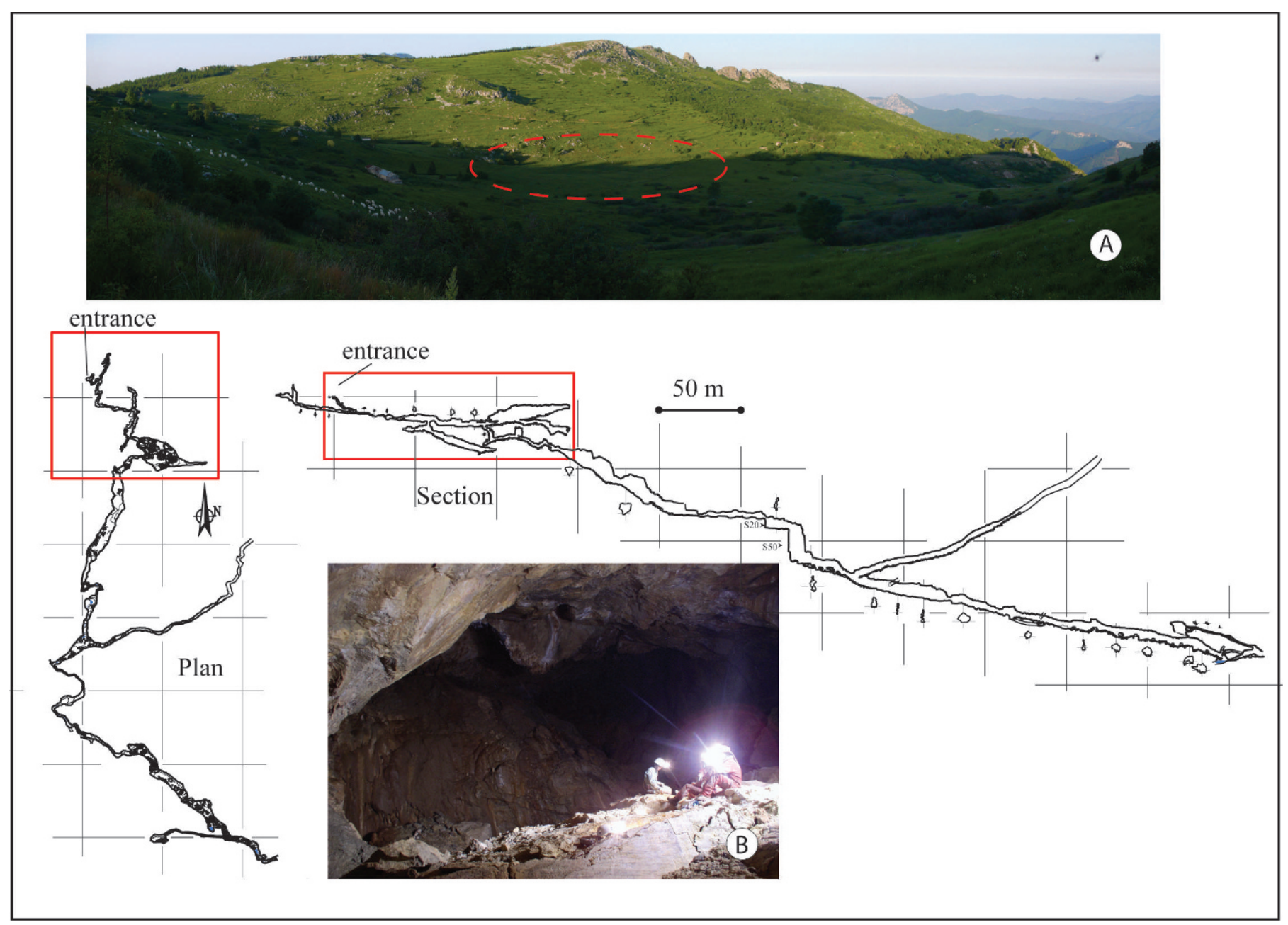

Figure 1. The survey area: (A) landscape of the Cartei da Colla plain; (B) picture of the largest room, which was the target of the geophysical experiment; partial plan and cross-section of the cave system. Cave survey performed with compass and tape.

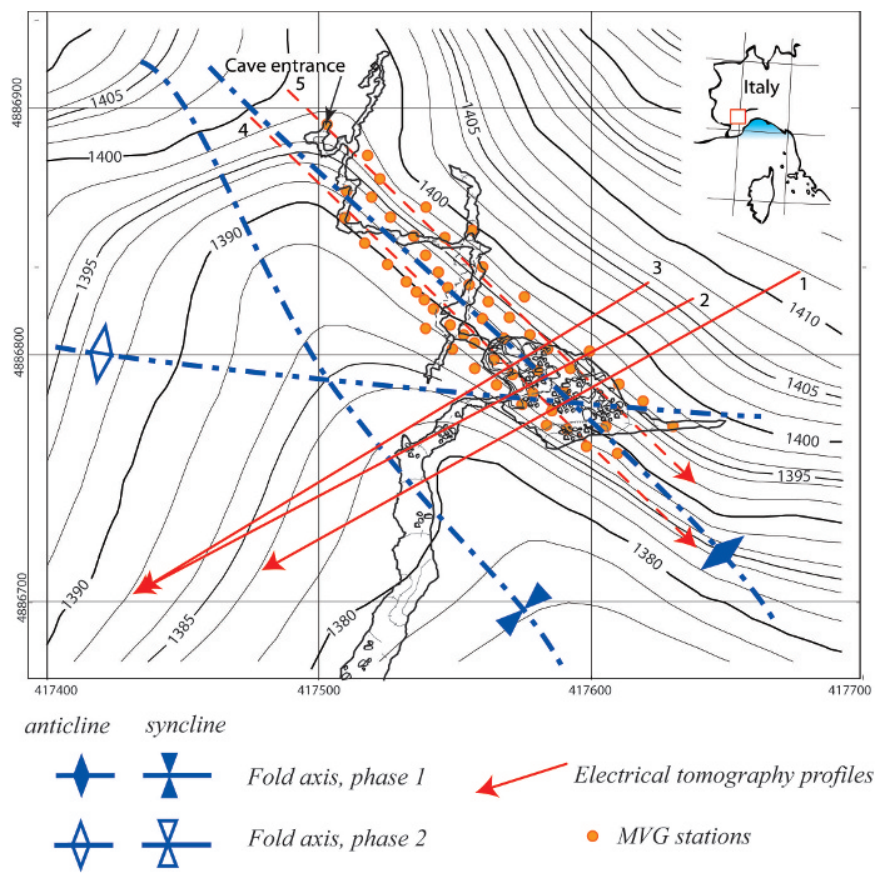

fractures trending $95^{\circ}$, with a prevailing drainage along the former. The deepest cave regions, conversely, exhibit an evolution along a fracture trending $135^{\circ}$ that cannot be recognized by surface observations.

\section{Geophysical Methods}

Five two-dimensional, direct-current electrical-resistivity traverses were carried out. The ERT prospecting was performed using a Syscal R1 (Iris Instruments) multielectrode system with a set of 48 electrodes evenly spaced every $5 \mathrm{~m}$. A Wenner-Schlumberger array configuration was used with a geometrical factor, $k=\pi(n+1) a$, where $a$ is the potential-electrode spacing and $n$ is an integer. The Wenner-Schlumberger array combines the standard individual Wenner and Schlumberger arrays, but is adapted for

Figure 2. Topography of the survey area, with structural features and the outline of the cave. 


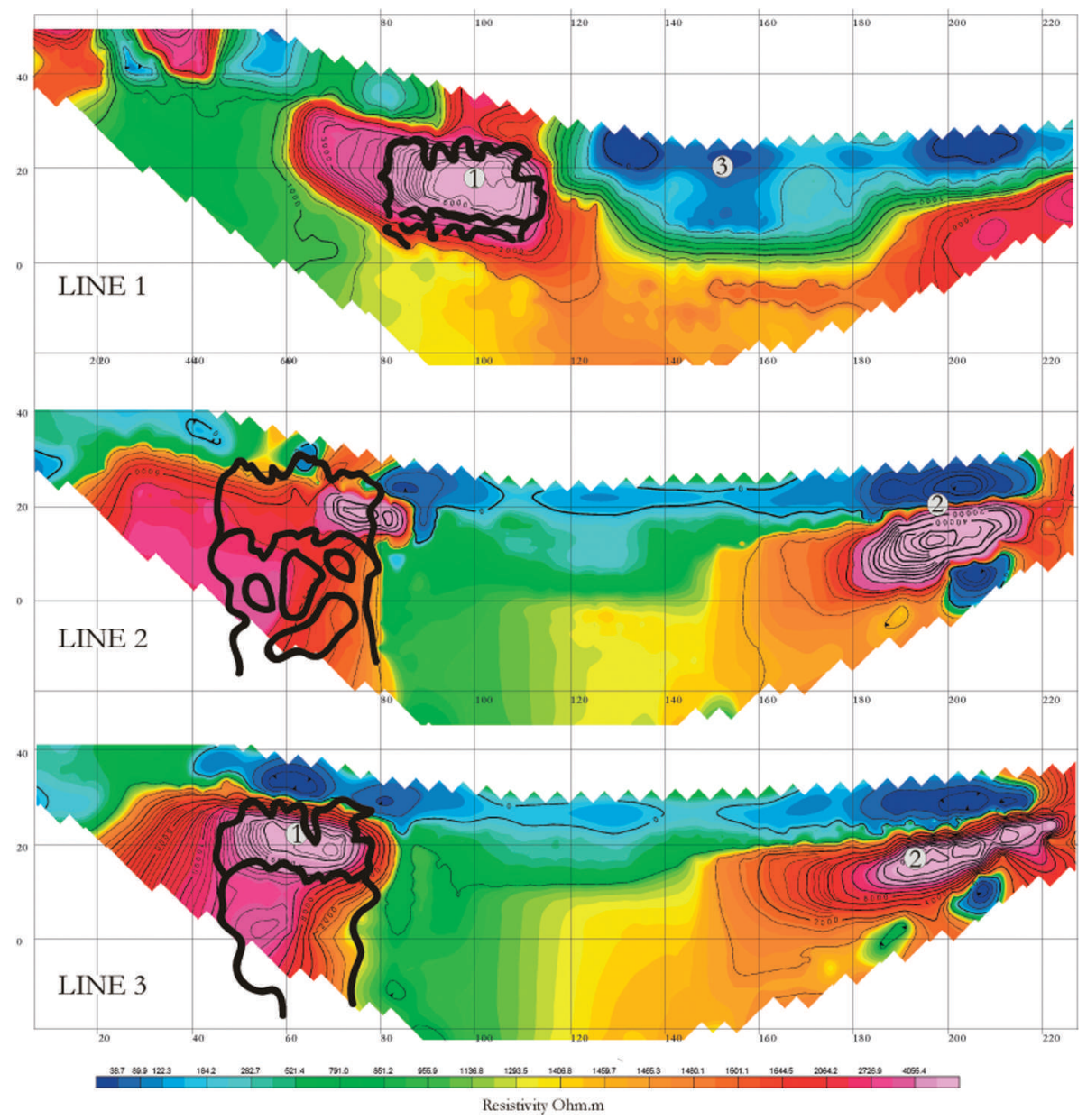

Figure 3. Electrical-resistivity tomography result for lines 1, 2, and 3 with the outline of the main room (see Fig. 2).

use with a line of electrodes with constant spacing, as normally used in 2-D imaging. Besides better horizontal coverage, the maximum depth of penetration of this array is about 1.5 times greater than the Wenner array (Loke and Barker, 1996). The measured resistance values are first reduced to apparent resistivity values and then inverted (Loke and Barker, 1996) to image the resistivity distribution below the traverse path (Fig. 3).

The MVG survey was performed using a LaCosteRomberg model D gravity meter, equipped with digital data acquisition through the Aliod feedback system, GPS tracking, and automatic tide correction. The meter has a nominal resolution of one microgal $\left(10 \mathrm{~nm} \mathrm{~s}^{-1}\right)$. The geographical positions of the 53 gravity stations (Fig. 2) were determined by using a differential GPS. The vertical gradient of the gravity field was measured as the ratio between the difference of two recordings at different heights and the height difference. Measurements were recorded for five minutes at the top and bottom of a 1.80meter tower. The recording procedure included a tide correction. The recordings can be statistically averaged to give a best estimate of the gravity, reducing the noise inherent within a single measurement resulting from instrumental errors, vibrations of the support, and other related sources of uncertainty. The gravity data were processed to remove the instrument drift, determined by periodically reoccupying the gravity base station located near the survey area. The observed drift error was about $25 \mu \mathrm{gal} \mathrm{d}^{-1}$. The overall error of the MVG data, including effects of nearby topography, tide, and drift was approximately 4 to $5 \mu \mathrm{gal} \mathrm{m}^{-1}$ (Stefanelli et al., 2008).

\section{Results AND DAta InTERPRETATION}

Figure 3 shows the results of the inversion (Loke and Barker, 1996) of apparent resistivity data collected along profiles 1, 2, and, 3 that cross the main room. The crosssection of the room is superimposed on the plots. The results from traverses number 4 and 5 appear to be much noisier than the others, even though the cave outline is still recognizable. Because of the high noise, these results are not shown.

The resistivity values associated with the room range from 6,000 to 40,000 ohm-m (Fig. 3, line 1). The high variability of the void's electrical signature may be due to a micrometeorological effect inside the cave. A seasonal cave 


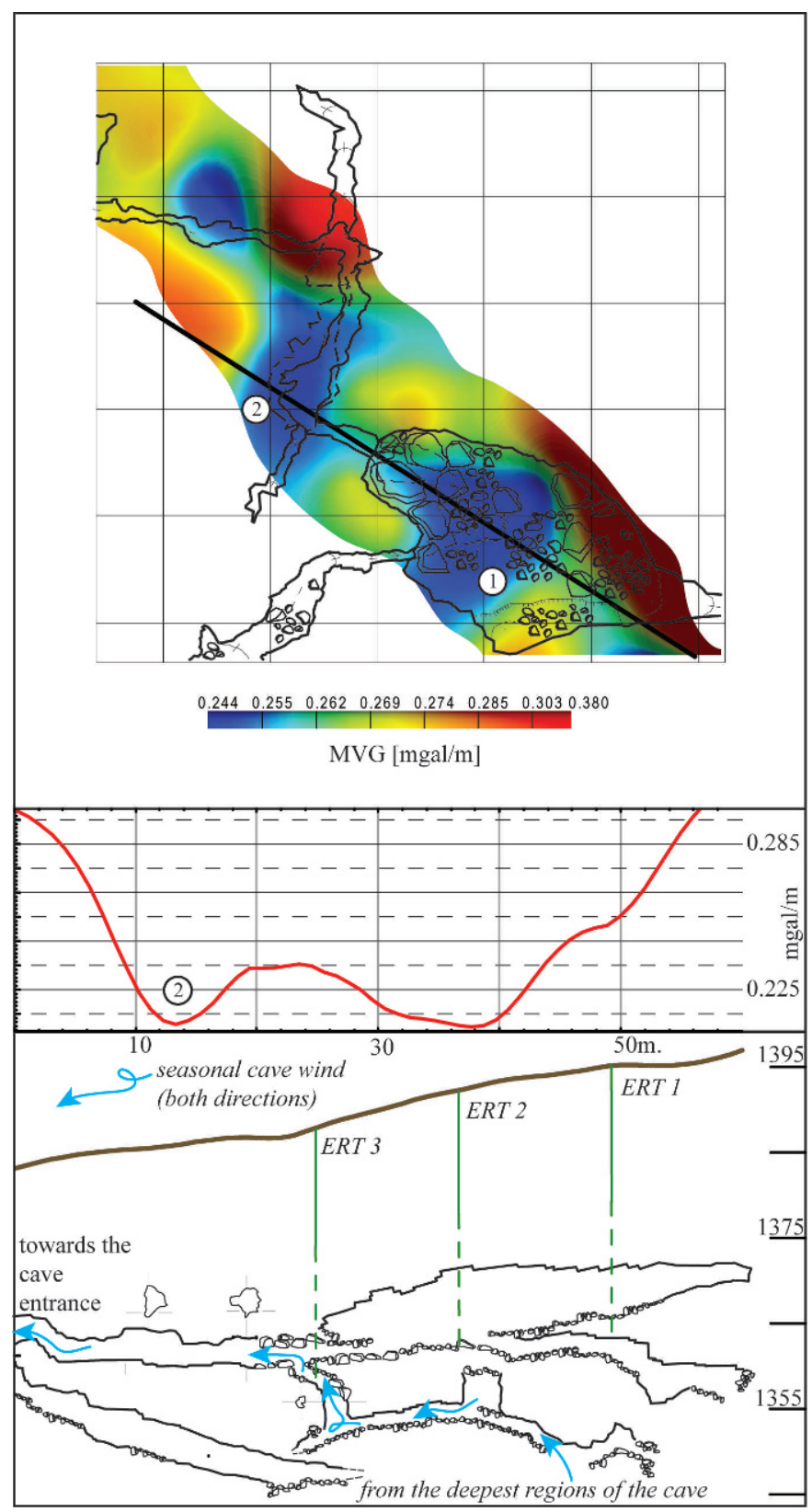

Figure 4. The microgravity vertical-gradient survey. Top panel, spatial distribution of the gradient; bottom panel, profile with the cave cross-section.

wind (Fig. 4) flows from the deepest regions towards the entrance, yielding a significant decrease in cave moisture. This air flow dries the cave walls, thus increasing their electrical resistivity; conversely, the parts of the cave far from the wind path are much more damp, and thus the resistivity drops. This effect is clearly shown in the sections for lines 1 and 3. Line 2, conversely, shows lower resistivity values than line 3 . This may be due to the fact that the passages between the area of line 3 and the large room probed by line 1 are filled with large debris and blocks.
The ERT survey shows an unpredicted oval-shaped maximum of resistivity (labeled 2 in Fig. 3) and is interpreted as evidence of an unknown cave. The welldefined low-resistivity body (labeled 3 in Fig. 3) is interpreted as a sinkhole filled with residual clays.

The distribution of MVG data with the cave-plan outline are shown in the upper panel of Figure 4. The lower panel of Figure 4 shows a profile across the main hollow. There is a very good correlation between the horizontal geometry of the cave and the minima of the gradient map, as it is expected from the large negative density contrast between voids and rocks $\left(-2400 \mathrm{~kg} \mathrm{~m}^{-3}\right)$. This shows that effects of local topography have been effectively filtered out in the gradient measurements. The gradient survey had a mean value of $0.268 \mathrm{mGal} \mathrm{m}^{-1}$, in contrast with the standard vertical gradient value of approximately $0.3 \mathrm{mGal} \mathrm{m} \mathrm{m}^{-1}$. This may result from the superposition of the localized negative anomaly that is well-correlated to the cave geometry and a more general regional feature coming from other large-scale geological effects. The amplitude of the gradient varies across the area by approximately $0.130 \mathrm{mGal} \mathrm{m} \mathrm{m}^{-1}$ because of the large underground voids. The gradient profile exhibits a negative anomaly approximately coincident with the known void geometry. The minimum above the largest room (Figure 4, labeled 1) is consistent with the presence of a large (about $20 \times 20 \times$ $80 \mathrm{~m}$ ) collapsed pit partially filled by collapse debris. The minimum labeled 2 in Figure 4 is attributed to the two underlying levels of cave passage.

\section{Conclusions}

The combined application of microgravity verticalgradient sounding and electrical resistivity tomography yields accurate imaging of underground hollows. The MVG shows minima coincident with the known void, showing a capability for void detection. The ERT results, combined with of the cave location and volume supplied by MVG, can give high-resolution images of underground voids. The low cost and the moderate logistics needs of both methods allow rapid noninvasive surveys, providing reliable results.

\section{ACKNOWLEDGMENTS}

The authors wish also to thank R. Castello and F. Poggi (Environment Department, Regione Liguria) for their confidence in the Speleology and Nature in Pennavaire High Valley (SNAP) Research Project, which has been funded by the department act n.1543 02/12/2005, granted to the Alassio Caving Club. Thanks are also due to the municipal authorities of Alassio and Alto for logistical support and permission to access the caves. The authors also acknowledge the assistance provided by the Alassio Caving Club and E. Massa and A. Maifredi in the underground survey. 


\section{REFERENCES}

Field, M., 1993, Karst hydrology and chemical contamination: Journal of Environmental Systems, v. 22, no. 1, p. 1-26.

Loke, M.H., and Barker, B.R., 1996, Rapid least squares inversion of apparent resistivity pseudosections by a quasi-Newton method: Geophysical Prospecting, v. 44, p. 131-152.

Menardi-Noguera, A., 1988, Structural evolution of a briançonnais cover nappe, the caprauna-armetta unit (Ligurian Alps,
Italy): Journal of Structural Geology, v. 10, no. 6, p. 625637.

Stefanelli, P., Carmisciano, C., Caratori Tontini, F., Cocchi, L., Beverini, N., Fidecaro, F., and Embriaco, D., 2008, Microgravity vertical gradient measurement in the site of Virgo interferometric antenna (Pisa Plain, Italy): Annals of Geophysics, v. 51, no. 5-6, p. 877-886.

Waltham, T., Bell, F.G., and Culshaw, M.G., 2005, Sinkholes and subsidence: Karst and cavernous rocks in engineering and construction, Chichester, U.K., Springer, 382 p. 